\title{
Spillover Effects among Network Neighbors: Evidence from Telecommunications of China
}

\author{
Zhaoyou Zeng ${ }^{1}$ Zhihe Long $^{2}$ Jiajun Lai $^{3}$ \\ ${ }^{1}$ School of Economics \& Management, Southwest Jiaotong University, Chengdu 610031, P. R. China \\ ${ }^{2}$ School of Business Administration, South China University of Technology, Guangzhou 510640, P. R. China \\ ${ }^{3}$ School of Information Science \& Technology, Southwest Jiaotong University, Chengdu 610031, P. R. China
}

\begin{abstract}
As information technologies support more freedom of industrial location. Local governments, in order to increase their own output, may use telecommunications investment as a competitive tool for attracting factors of production. This effect, in a production-function framework, would manifest itself as a negative output spillover effect to other provinces from telecommunications investment. This paper tests for spatial spillover effects of province level telecommunications services on province output by using spatial panel data for 30 provinces in China from 1993 through 2004. Findings indicate that a province benefits from its own telecommunications development, but the level of telecommunications services (it reflects development) in its "network neighbors" has a negative impact on its output.
\end{abstract}

Keywords: Spatial spillover, Network neighbor, Moran's I

\section{Introduction}

In China, the reform geared to the needs of market economy has brought this country many great changes. The mobility of factors of production countrywide has a great increase than before. Local governments have more power to participate in regulating economic activities.

Moreover, in the past 30 years, technological revolutions have hit the industrial world. Telecommunications as an important factor [1]-[3], emerged in interregional economic activities [4]-[13]. As all non-neighbor localities become more accessible and in some sense closer to each other, firms can now establish and maintain contacts with suppliers and customers over greater distances. In fact, the advancements in information technology have diminished the importance of geographic proximity and created new "network neighborhoods". Therefore, such advanced technologies may alter location decisions of firms, the search by firms for the least cost location is likely to reshape regional development patterns, which will lead to higher rates of growth for better endowed regions[14]-[17].

In China telecommunications networks are public owned. Central government and local governments through their regulatory power both have important impact on the telecommunications investment. Local regulatory agencies improve telecommunications services in pursuit of higher rates of growth.

Given that provinces have such a policy tool that affects the availability of telecommunications investment, it is reasonable to expect that local policymakers may use this tool to attract factors of production from other regions. When firms search for the better telecommunications services move to better endowed provinces, the increase in these provinces' output will, at least initially, come at the expense of their former location. In the production function framework; this effect could be manifested as a negative output spatial spillover effect from telecommunications development.

This paper tests for spatial spillover effects of province level telecommunications development on province output. Using a panel data set of output, labor, capital investment, and telecommunications development for 30 provinces between 1993 and 2004, we find that a province benefits from its own telecommunications development, but telecommunications development in other provinces has a negative effect on its output. Moreover, the results suggest that the "network neighborhood" has been of importance in interregional economic activities.

This study is different from the existing literature on follow ways: It is the first attempt to investigate the role of telecommunications services in China from a regional growth standpoint. In fact, telecommunications networks exhibit all the characteristics of an infrastructure network such as immobility, large initial investment, and presence of external economies [18]. Our analysis can provide 
insight how to use telecommunications services as a regional development tool.

Second, this paper offers an alternative view of the impact of telecommunications on interregional economic patterns. The existing view is that geographic proximity is important in regional development because it is more easily in-migration of factors of production from geographic neighboring regions. However, firms can now compete for customers and raw materials across greater distances. The advancement of technology in telecommunications have reduced the role of geographic proximity, for instance, the most of skilled labor force in Guangdong province are from all over the country. Not from the adjacent provinces. Some recent studies show that local taxes, regional business climate, and availability and accessibility of basic infrastructure have been becoming very concernful factors in decisions of business location [19]-[20]. Network neighbors become the firms' actual outlook for business location and relocation. We test this proposition in terms of telecommunications services by investigating the impact of network distances on regional output growth.

This paper draws heavily on the tools and techniques used in recent work on spatial econometrics by [21]-[26], and the work on the spatial distribution of infrastructure systems in the regional science literature [27]-[29]. The existing literature on the spatial distribution of public infrastructure is not conclusive, and offers contradictory results on both the existence and the sign of the spillover effects. We expect that this study, using evidence in China, will make a contribution to this ongoing debate.

The structure of the paper is as follows: Section 2 describes the conceptual framework and specifies the econometric model; Section 3 discusses data and presents the results. Section 4 presents test results for robustness of the empirical findings and Section 5 gives the conclusions and future directions of research.

\section{The model specification}

\subsection{Conceptual framework}

This section outlines a classical production model, where telecommunications investments are quasi-fixed inputs for gross province production (GDP). In our model we consider provinces as the unit of analysis because the province regulatory agencies can participate in designing policy for telecommunications development within their geographic boundaries.
In the study of [30], the output in each state is produced according to

$$
Q=\alpha(G) \beta(T K) f(K, L)
$$

Where $Q$ is output, $G$ is public capital stock, $T K$ is telecommunications capital stock, $L$ is labor input, and $K$ is private capital stock.

Both public infrastructure and telecommunications infrastructure in the model are assumed to be complementary to labor and capital.

Because the purpose of this paper is to test spillover effects of telecommunications services of network neighbors. We adopt their model as start point of analysis. It is as follow:

$$
G D P=\alpha(T) f(K, L)
$$

Where GDP is output, $\mathrm{T}$ is telecommunications investment, $\mathrm{L}$ is labor input, and $\mathrm{K}$ is capital input and equation (2) meets the following conditions

$$
\alpha^{\prime}(T)>0, f_{K}>0, f_{L}>0
$$

And $f_{K K}<0, f_{L L}<0$.

If the markets are competitive and the factors of production are mobile, then each input is paid its marginal revenue product, which depends on $T$

$$
\begin{aligned}
& \frac{\partial G D P}{\partial K}=\alpha(\mathrm{T}) \mathrm{f}_{\mathrm{K}}(\mathrm{K}, \mathrm{L}) \\
& \frac{\partial G D P}{\partial L}=\alpha(\mathrm{T}) \mathrm{f}_{\mathrm{L}}(\mathrm{K}, \mathrm{L})
\end{aligned}
$$

Then the factor prices in province $i$ become

$$
w_{i}=p \alpha(T) f_{L}\left(L_{i}, K_{i}\right)
$$

And

$$
r_{i}=p \alpha(T) f_{K}\left(L_{i}, K_{i}\right)
$$

This $\mathrm{p}, \mathrm{w}$, and $\mathrm{r}$ are the prices of output, labor, and capital, respectively.

As province $\mathrm{i}$ increases its investment in the telecommunications, from Equation (4) the price of labor and capital increase accordingly. With fully mobile labor and capital, one would expect to see factors of production move from other provinces to province $\mathrm{i}$ in the short run. Therefore, after factor migration, labor, and capital increase in province i and decrease in other provinces, and the output in province i would be

$$
G D P_{i}=\alpha(T+\Delta T) f\left(L_{i}+\Delta L, K_{i}+\Delta K\right)
$$

Therefore, ceteris paribus, migration of factors would result in output increases in provinces with 
well-developed telecommunications networks and output losses for others.

\subsection{Empirical model}

Boarnet argues that regions with the best infrastructure would bid mobile factors of production away from other regions. Competitive advantage from previous infrastructure investments would change the path of future investments in a region's economy, boost its output, and increase its competitiveness. Therefore, availability and quality of infrastructure services influence the economic performance of regions. Similarly, if telecommunications investment in a province enhances factors of production, the total output in that province would depend positively on its input of telecommunications, and negatively on the input of telecommunications in other provinces. Thus, we can reshape the production function for the province after including the spatial spillover as

$$
G D P=f(L, K, T, O T)
$$

Where GDP is province output, $L$ is labor, $K$ is capital investment, $T$ is telecommunications input in the province, and $O T$ is telecommunications input in all other provinces.

In Equation (6), OT is the spillover variable, and it captures the impact of the network neighborhood on province output. The paper hypothesizes that interconnectivity of the systems diminishes the role of physical borders and geographic distance, so we consider all provinces to be adjacent to each other in terms of access to communications. In our representation, the network neighborhood is defined as the weighted sum of telecommunications input in all other provinces. Spillover variables are calculated by using the formulas

$$
O T_{i t}=E_{t} W_{t} T_{j t} \quad(j: \text { All other provinces })
$$

This $\mathrm{W}$ is the weight matrix with elements $w_{i j}$ for each year, $i$ indexes the province under investigation and $\mathrm{j}$ indexes all other provinces in OT. Before introducing each of these neighbor variables we ran an F-test to assess whether or not inclusion of neighbor variables into the model has additional explanatory power. The procedure and the results of these tests will be discussed in the next section.

The matrix $\mathrm{W}$ is constructed so that the weight $w_{i j}$ is larger for provinces that are more similar. For our purposes, the weight matrix should reflect similarities in industrial composition of provinces. Yilmaz, Haynes, and Dinc [31] examined the impact of telecommunications capital on individual sectors and found that the impact was positive and statistically significant on service related sectors, whereas it was not statistically significant on others. Because of this greater interaction between telecommunications and service related sectors, the share of total service sector employment in total province employment is used as a measure of cross province similarity for a given province. It is assumed that provinces with similar sectoral structures are potential rivals in competing for the same mobile factors of input (e.g. Serdar Yilmaz, Kingley E. Haynes, Mustafa Dinc (2002)). Therefore, the weight matrix should reflect similarity of these locational characteristics of provinces for telecommunications investment. The general formula for the weights in these weight matrices is

$$
w_{i, j}=\left(1 /\left|P_{i}-P_{j}\right|\right) / \sum_{j=1}^{29} 1 /\left|P_{i}-P_{j}\right| \text {. }
$$

This $P_{i}$ is proportion of service employment to total employment in province $i$ and $P_{j}$ is the counterpart in the network neighbor definition (see [29]-[31]).

The matrix $E$ is reflection of affect power of the economic base between province $i$ and its neighbor. The general formula is:

$$
\begin{gathered}
E_{i j}=\left\{\begin{array}{c}
\frac{1}{\left|\overline{G D P_{i}}-\overline{G D P_{j}}\right|}, \quad \text { if } i \neq j \\
0, \text { if } i=j \\
\overline{G D P_{i}}=\frac{1}{T} \sum_{t=1993}^{T} G D P_{i t}, T=1993, \ldots 2004
\end{array}\right.
\end{gathered}
$$

The regression model is based on the log-linear Cobb-Douglas aggregate production function for provinces, including a spillover variable, as presented in Equations (6)

$$
\begin{aligned}
& \log \left(G D P_{i t}\right)=\beta_{1} \log \left(L_{i t}\right)+\beta_{2} \log \left(K_{i t}\right)+ \\
& \beta_{3} \log \left(T_{i t}\right)+\beta_{4} \log \left(O T_{i t}\right)+\gamma_{t}+f+\varepsilon_{i t}
\end{aligned}
$$

Where $\gamma$ is a vector of year specific intercepts and $f$ is a vector of time-invariant province effects.

Equation (7) represents the main model for our analysis. The anticipated coefficients $\beta_{1}, \beta_{2}, \beta_{3}$ are positive. $O T_{i t}$ variable represents spillover effect. For this variable, a negative sign would imply that locations with better telecommunication services will experience output grow that the expense of others, in other words, negative spillover effects exist; a positive sign can be interpreted as an indicator of the existence of positive externalities; that is, the expansion of telecommunication input in a province will increase output in other provinces. 


\section{Empirical analyses}

\subsection{Data set}

The output variable is represented by the total output of province-level. The labor variable represents the total employment by place of work in a province for a given year. Capital investment data are from raw data in China Statistical Yearbook, computed follow Perpetual Inventory Method

Telecommunications input in each province can not be obtained directly. This study use the last year's Telecommunication Services data replace it, because Telecommunication Services data which lagged one year is not only relative to Telecommunication input but also reflects level of services can be supplied by telecommunication industry in the province in current year. Its role is similar to public infrastructure.

Output, labor and capital investment, and telecommunication services data are from China Statistical Yearbook edited by National Bureau of Statistics. All monetary values are calculated at 1990's constant prices.

\subsection{Empirical results}

Access to panel data reduces the collinearity among explanatory variables and gives enough degrees of freedom to estimate more robust results, hence improving the efficiency of econometric estimates [16]. However, previous research shows that in this type of panel data analysis the estimation results might be subject to econometric problems. One is the issue of serial correlation. In the case of serial correlation, the variables should be transformed into differences to alleviate the serial correlation problem, or else, panel data estimates may result in even more biased estimates than simple OLS estimations using cross sectional data alone. Bhargava, Franzini, and Narendranathan in [32] provide a test for serial correlation in panel data sets. We can apply the BFN test to the level form estimation of the model. The BFN statistic of $d_{p}$ is above the critical value. It suggests that the variables mustn't be transformed into differences forms, in other words, serial correlation in this analysis can be ignored.

Table 1 presents the results of generalized least squares (GLS) estimation of the production function specified in Equation (7) without a spillover variable. The model treats the level of telecommunication services as a factor input in the production function framework. The coefficient on $T$ variable is positive and statistically significant, suggesting that provinces benefit from an increase in their telecommunications input. This finding is consistent with the existing literature on telecommunications infrastructure and economic growth.

\begin{tabular}{ll}
\hline Log(independent variable) & Dep- variable: $\log ($ GDP $)$ \\
\hline Labor & $0.613^{*}(0.013)$ \\
capital investment & $0.504^{*}(0.009)$ \\
Telecom- services & $0.009^{*}(0.003)$ \\
Adjusted $\mathrm{R}^{2}$ & 0.76 \\
\hline
\end{tabular}

Remark: *indicates one percent significant; Standard errors are in parentheses

Table 1: Regression Results of Basic Model.

Capital investment and labor variables also have expected signs (indicating that all positively contribute to output) and are statistically significant.

We tested the negative spillover hypothesis by using the econometric specification in Equation (7). In specifications 1 , an additional variable representing network neighbor definition is excluded from the basic model. Specification 2 has the additional variable in it, so specification 1 is the restricted, and specification 2 is the unrestricted form of the econometric model.

To test the validity of relaxing this restriction, i.e., if spillover variable should be introduced to the model, and performed F-tests. $\mathrm{F}_{\mathrm{r}, \mathrm{n}-\mathrm{k}}=[(\mathrm{SSEr}-\mathrm{SSEu}) / \mathrm{r}] /$ $(\mathrm{SSEu} / \mathrm{n}-\mathrm{k})=6.97>\mathrm{F}_{\text {critical }}(5$ percent level $)=3.89$. The F score for the model is greater than the critical $F$ value in the analysis period. The null hypothesis that the spillover variable has no explanatory value is rejected for the models. It means that inclusion of the neighbor variable has more explanatory power. In order to estimate spillover effects of telecommunications services in all other provinces, the network neighborhood variable is included in model (7).

As seen in Table 2, during the whole period the sign of the network neighbor variable is negative and significant, supporting the negative spillover argument. This estimation results support our negative spillover hypothesis. A given province's own telecommunications services have a positive impact on the province's output whereas neighbors' telecommunications services have a negative impact. Overall, the elasticity of telecommunications services could be interpreted as follows, when all provinces change their rate of telecommunications services by one percent, the net change in output growth rate in any province is the sum of coefficients on the telecommunications services and neighbor variable.

\section{Robustness of results}




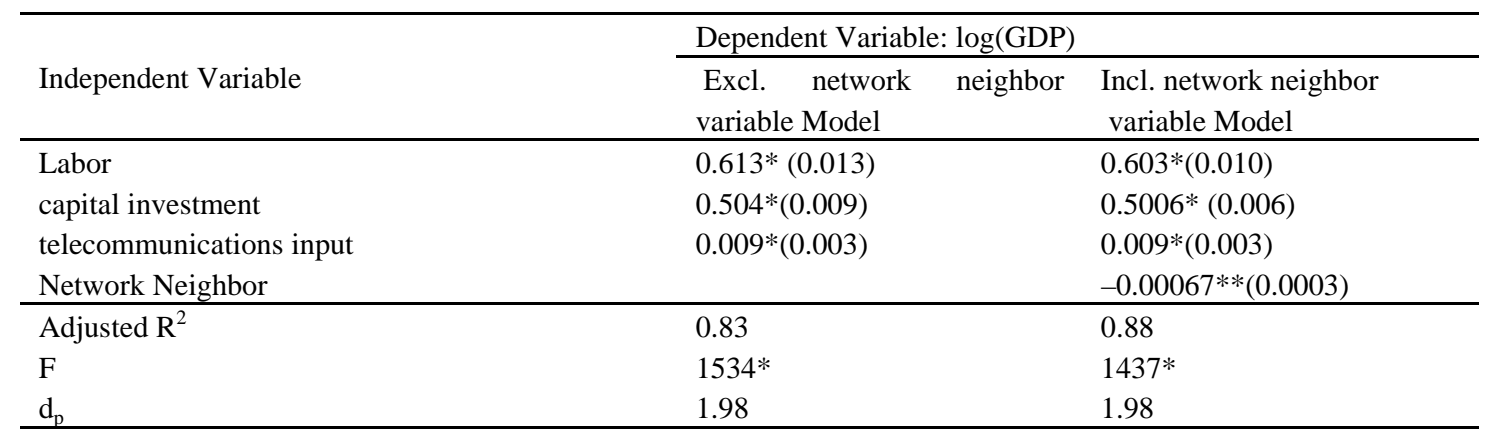

Remark: *indicates one percent significant; **indicates five percent significant; Standard errors are in parentheses.

Table 2: Regression Results.

Two common problems in the regional development literature that contaminate the estimation results are reverse causality [33]-[35] and spatial interaction problems [34]-[38]. In this section, we perform additional tests to assess the robustness of our findings.

\subsection{Reverse causality}

A good method for testing reverse causality is vector autoregressive techniques described in [34]. To test the reverse causal link between output and telecommunications services, we specify a vector autoregression containing two, three lags of output growth and growth in telecommunications services. The estimation results cannot reject the null hypothesis, which is the coefficients on output growth equal zero .So, in the analysis period, we can not think the reverse causality between output and telecommunications services exists.

\subsection{Spatial interaction}

If spatial effects be ignored, the presence of spatial dependence and spatial heterogeneity may lead to misspecification of models, and cause bias in estimator.

In this section, we conduct additional tests to address spatial interaction issues and to assess the robustness of our estimates. One of the main reasons for spatial correlation or dependence in the error terms of regionnal econometric models is omitted variables that may relate to the connectivity of neighboring regions [39]. In a properly specified model, it is quite likely that spatial dependence would be reduced or eliminated.

An important issue in an empirical analysis is to detect the presence of spatial effects and distinguish between cases when spatial dependence is a nuisance and cases when spatial dependence is a substantive spatial process. Spatial error dependency is not the only source of the spatial interaction problems. In addition to a mismatch between real boundaries of variables and boundaries of compile data might result in nuisance dependency. In most cases, the data employed in the analysis may exhibit a spatial interrelation because of spatial proximity.

Moran's I test is a well-known test for spatial interaction. The results of the Moran's I test (given in Table 3) are highly insignificant for all the years in the analysis period; hence, in this empirical analysis, spatial interaction is not a concern.

\begin{tabular}{|l|lll|}
\hline & \multicolumn{3}{|c|}{ Equation (7) } \\
\hline Year & Moran's I & z-value & P \\
\hline 1993 & -0.069 & -0.40 & 0.710 \\
\hline 1994 & -0.021 & -0.17 & 0.87 \\
\hline 1995 & -0.064 & 0.37 & 0.69 \\
\hline 1996 & -0.080 & -0.43 & 0.89 \\
\hline 1997 & -0.039 & -0.21 & 0.76 \\
\hline 1998 & -0.130 & -0.13 & 0.67 \\
\hline 1999 & -0.068 & 0.12 & 0.85 \\
\hline 2000 & -0.050 & -0.45 & 0.69 \\
\hline 2001 & -0.078 & -0.44 & 0.73 \\
\hline 2002 & -0.089 & -0.70 & 0.57 \\
\hline 2003 & -0.303 & 0.42 & 0.86 \\
\hline 2004 & -0.079 & -0.46 & 0.72 \\
\hline
\end{tabular}

Table 3: Moran's I Tests for spatial effects.

The finding in this empirical analysis suggests that the spatial interaction have no considerable impact on our foregoing conclusion. It offers seemingly contradictory to result of some existing literature.

In fact, in the model of this analysis, the definition of spatial spillover variable $O T$ has included spatial interaction of interregion. In other words, the spatial interaction of interregion has been included in the value of $O T$ variable.

\section{Conclusions}


In this study, we examined the impact of telecommunications services on province output using a panel data set for 30 provinces in China. Our results from the fixed effect model indicate that a province's output growth rate is positively related to its level of telecommunications services, and negatively related to counterparts in other provinces. These findings suggest that telecommunications services (which depended on telecommunications investment) is an important factor for a province's output growth, but it has a negative spillover effect for other provinces.

The findings suggest that the network neighborhood play an important role in interregional economic activities now. We tested the popular view of the impact of negative spillover is from network neighbors. Furthermore, the results are robust when the spatial interaction problem is taken into account. Overall, the evidence supports the idea that telecommunications services has a significant positive impact on a province's output and provinces with similar telecommunications input compete for mobile factors of production.

These findings have important implications for policymakers. Our findings suggest that viewing telecommunications as a purely public good (without taking into account its use as a factor of production) may result in overestimation of the positive externalities. Though the overestimation of positive externalities would be minor because the magnitude of negative spillovers is small, the existence of negative spillover effects marks not all externalities can be internalized. The subsidy scheme may be inefficient.

Secondly, the presence of a negative spillover effect suggests that provinces may use telecommunications policy as a competitive tool to enhance their own output growth rather than in pursuit of socially optimal goals. This induces each region to provide more telecommunications services than it would have otherwise provided. In this context, if local governments and the central government pursue different goals, the agency problem between the central government and the local government may result in suboptimal levels of telecommunications investment. This behavior of "beggar-thy-neighbor" competition, from the agency theory point of view, will reduce the social benefit of telecommunications input.

In this paper, the empirical evidence supports the negative spillover hypothesis. Some interesting questions for further research are whether geographic proximity amplifies the negative spillover effects in China.

\section{Acknowledgement}

This work was partially supported by the National Science Foundation of P.R. China under Grant No. 60474022, and the specialized Research Fund for the Doctoral Program of Higher Education of China under Grant No. 20060613007.

\section{References}

[1] C. Antonelli, Investment, Productivity Growth and Key Technologies: The Case of Advanced Telecommunications, the Manchester School, 60:386-397, 1993.

[2] W.S. Norton, Transaction Costs, Telecommunications, and the Microeconomics of Macroeconomic Growth, Economic Development and Cultural Change, 41:175-196, 1992.

[3] J.F. Cronin, M.A. Gold, B.B. Mace, and J.L. Sigalos, Telecommunications and Cost Savings in Educational Services, Information Economics and Policy, 6:53-75, 1994.

[4] J.F. Cronin, C. Elisabeth and M.A. Gold, Telecommunications, Factor Substitution and Economic Growth, Contemporary Economic Policy, XV: 21-31, 1997.

[5] J.F. Cronin, C. Elisabeth, P.L. Herbert and L. Steve, Telecommunications and Growth the Contributions of Telecommunications Infrastructure Investment to Aggregate and Sectoral Productivity, Telecommunications Policy, 17:677-690, 1993.

[6] J.F. Cronin, M.A. Gold, P.L. Hebert and L. Steve, Factor Prices, Factor Substitution, and the Relative Demand for Telecommunications across U.S. States, Information Economics and Policy, 5:73-85, 1993.

[7] J.F. Cronin, M.M. Patricia, M.R. Miller, and E.B. Parker, The Rural Economic Development Implications of Telecommunications Evidence from Pennsylvania, Telecommunications Policy, 19: 545-559, 1995.

[8] M. Dinc, E.H. Kingsley, R.S. Roger and S. Yilmaz, Regional Universal Telecommunication Service Provision in the U.S. Telecommunications Policy, 22:541-553,1998.

[9] S.W. Baer, Telecommunications Infrastructure Competition the Cost of Delay, Telecommunications Policy, 19:351-363, 1995.

[10] H.N. Leff, Externalities, Information Costs, and Social Benefit-Cost Analysis for Economic Development: An Example from Telecommunications, Economic Development and Cultural Change, 32:255-276, 1984.

[11] S.A. Genio, E.R. Sepulveda, P.A. Dilworth and S.A. Shaikh, Industry Structure, Productivity and 
International Competitiveness: The Case of Telecommunications, Information Economics and Policy, 6:121-142, 1994.

[12] M. Gary and S.J. Savage, CEE Telecommunications Investment and Economic Growth, Information Economics and Policy, 10: 173-195, 1998.

[13] R.R. Dholakia and H. Bari, Telecommunications and Economic Development Econometric Analysis of the U.S. Experience, Telecommunications Policy, 18: 470-477, 1994.

[14] E. Paul and K. Georgios, Are Government Activities Productive? Evidence from a Panel of U.S. States, Review of Economics and Statistics, 76:1-11, 1994.

[15] M.E. Gramlich, Infrastructure Investment: A Review Essay, Journal of Economic Literature, XXXII: 1176-1196, 1994.

[16] H.E. Kingsley, D.H. Good and T. Dignan, Discrete Spatial Choice and the Axiom of Independence from Irrelevant Alternatives, SocioEconomic Planning Sciences, 22:241-251, 1988.

[17] M.A. Brian and W.J. Randall, The Role of Space in Public Capital Research, International Regional Science Review, 23:235-259, 2000.

[18] T.R. Lakshmanan, Infrastructure and Economic Transformation in Åke E. Andersson (ed.) Advances in Spatial Theory and Dynamics, Amsterdam: North-Holland, 1989.

[19] J.F. Cronin, E.B. Parker, E. Colleran and M.A. Gold, Telecommunications Infrastructure and Economic Growth an Analysis of Causality, Telecommunications Policy, 15:529-535, 1991.

[20] P.J. Blair and R. Premus, Location Theory, in Richard D. Bingham and Robert Mier (eds.), Theories of Local Economic Development, California: Sage Publications, pp:121-144, 1993.

[21] A. Cliff and K. Ord, Testing for Spatial Autocorrelation among Regression Residuals, Geographical Analysis, 4:267-284, 1972.

[22] L. Anselin. Spatial Econometrics, 1999.

[23] B.H. Baltagia, S.H. Song and W. Kohc, Testing panel data regression models with spatial error Correlation, Journal of Econometrics, 117:123150, 2003.

[24] L. Anselin, Under the hood Issues in the specification and interpretation of spatial regression models, Agricultural Economics, 27: 247-267, 2002.

[25] A. Maria, H.L.F. de Groot and R.J.G.M. Florax, Space and Growth: A Survey of Empirical Evidence and Method, Space and Growth TI Tinbergen Institute Discussion Paper, 2004.
[26] R.J.G.M. Florrax and V.V. Arnoj, Spatial Econometric Data Analysis: Moving Beyond Traditional Models, International Regional Science Review, 26(3): 223-243, 2003.

[27] H.E. Douglas and A.E. Schwartz, Spatial Productivity Spillovers from Public Infrastructure: Evidence from State Highways, International Tax and Public Finance, 2:459-468, 1995.

[28] M.G. Boarnet, Highways and Economic Productivity: Interpreting Recent Evidence, Journal of Planning Literature, 11:4-12, 1997.

[29] M.G. Boarnet, Infrastructure Services and the Productivity of Public Capital: The Case of Streets and Highways, National Tax Journal, 50: 39-57, 1997.

[30] S. Yilmaz, K.E. Haynes and D. Mustafa, Geographic and Network Neighbors: Spillover Effects of Telecommunications Infrastructure, Discussion Paper 42:339-360, 2002.

[31] S. Yilmaz, K.E. Haynes and D. Mustafa, The Role of Telecommunications Infrastructure on Regional Growth, Working Paper No. 2000-5, 2000.

[32] C. Hsiao, Analysis of Panel Data, 2nded. Cambridge: Cambridge University Press, 2003.

[33] B. Aruna, L. Franzini and N. Wiji, Serial Correlation and the Fixed Effects Model, Review of Economic Studies, 49: 533-549, 1982.

[34] H.E. Douglas, W. Newey and H.S. Rosen, Estimating Vector Autoregression with Panel Data, Econometrica, 56:1371-1395, 1988.

[35] H.E. Douglas, Public Sector Capital and the Productivity Puzzle, Review of Economics and Statistics, 76:12-21, 1994.

[36] C. Frazier and K.M. Kockelman, Spatial Econometric Models for Panel Data: Incorporating Spatial and Temporal Data, Transportation Research Record. The 84th Annual Meeting of the Transportation Research Board, 2005.

[37] W.C. Lu, J.R. Chen and C.L. Wang, R\&D, Spatial Spillovers and Productivity Growth: Evidence from Dynamic Panel, 2005.

[38] J.P. Elhorst, Specification and Estimation of Spatial Panel Data Models. International Regional Science Review, 26(3):244-268, 2003.

[39] H.H. Kelejian, I.R. Prucha, A generalized spatial Two-Stage Least Squares procedure for estimating a spatial autoregressive model with autoregressive disturbances, Journal of Real Estate Finance and Economics, 17:99-121, 1998. 